\title{
UNIVERSALITAS AJARAN ISLAM
}

\section{Fadhlina Arief Wangsa}

Jurusan Ilmu Hadis (ILHA)

Fakultas Ushuluddin dan Filsafat UIN Alauddin

E-mail: efawe70@gmail.com

\section{Abstrak}

Penjelasan tentang konsep Studi Islam Komprenhensif dalam perspektif Qur'an dan Hadis Nabi SAW. menunjukkan bahwa Islam adalah agama yang Universal. Kata Islam tidak mempunyai hubungan dengan orang, golongan dan negri tertentu. Islam adalah nama yang diberikan oleh Allah SWT. yang tidak hanya mendatangkan rahmat bagi manusia, tetapi lebih dari itu, Islam datang untuk rahmat bagi alam semesta. Tidak hanya bagi manusia, tapi juga binatang, tumbuhtumbuhan, dan lingkungan alam semesta. Di sisi lain, Islam juga merupakan ajaran yang sempurna dan menyeluruh yang mengatur keseimbangan hidup, antara dunia dan akhirat, membahas aspek-aspek kehidupan secara menyeluruh. Hadis yang terkait dengan berbuat baik pada hewan sembelihan, dengan cara menajamkan pisau, larangan menelantarkan tanah. Demikianlah ajaran Islam, yang tak dapat dilihat atau difahami secara parsial saja, yang dikhawatirkan akan menimbulkan kesalah fahaman tentang Islam itu sendiri. Oleh sebab itu, Allah memerintahkan untuk masuk ke dalam Islam secara menyeluruh.

\section{Keywords}

Universalitas , Ajaran, Islam

\section{Pendahuluan}

Kajian tentang Universalitas Ajaran Islam menurut penulis cukup signifikan, melihat fakta bahwa banyak orang memahami Islam dengan cara parsial, dan tidak holistik. 
Pengertian dari komprehensif itu sendiri berdasarkan kamus besar Bahasa Indonesia adalah: 1. Bersifat mampu menangkap (menerima) dengan baik; 2. Luas dan lengkap (tentang ruang lingkup atau isi); 3. Mempunyai dan memperlihatkan wawasan yg luas; ${ }^{1}$ Dapat dikatakan bahwa Universalitas Ajaran Islam adalah bagaimana memahami ajaran-ajaran Islam secara baik, utuh dan menyeluruh; Dalam hal ini, penulis sejalan dengan apa yang dikatakan oleh Prof. Dr. Harun Nasution, bahwa Islam bila ditinjau dari berbagai aspeknya, bukan hanya Teologi, atau suatu ajaran Fiqih tertentu. Hal ini menurutnya, tidak dapat mewakili keseluruhan dari ajaran Islam, karena ajaran Islam juga mengcakup kebudayaan, sejarah, falsafah, akhlak dan lain sebagainya. ${ }^{2}$

Walaupun Islam lahir di Negara 'Arab, bukan berarti bahwa semua masyarakat muslim di belahan dunia, harus mengikuti symbol-simbol 'Arab dan memasukkannya dalam budaya mereka. Sebagaimana pendapat Gus Dur, yang tidak setuju terhadap 'Arabisasi yang menjadi Islamisasi. Islam menurutnya tidak dapat dapat diwakilkan dengan symbolsimbol atau kata-kata yang bernuansa 'Arab, sementara yang tidak bernuansa 'Arab tidak dikategorikan sebagai Islam. ${ }^{3}$

Di sisi lain, Hadis Nabi SAW., sebagai sumber hukum Islam yang kedua setelah al-Quran, dan fungsinya sebagai penjelas, pada hakekatnya, juga telah menjelaskan ajaran Islam secara komprehensif tersebut, dalam matan Hadis yang berbeda-beda.

${ }^{1}$ http://kbbi.web.id/komprehensif. Diakses tanggal 09 Juni 2014.

2 Harun Nasution, Islam Ditinjau dari Berbagai Aspeknya, Jilid I, (Jakarta: Penerbit Universitas Indonesia, 1985), hlm. 27-28.

3 'Abdurrahman Wahid, Islamku, Islam anda Islam Kita, Agama Masyarakat Negara Demokrasi, Cet. I, (Jakarta: The Wahid Institute, 2006), hlm. 244-245. 


\section{Islam Agama Universal}

Menurut Nata Abuddin, dasar pengkajian Islam secara komprehensif, sebenarnya dapat ditelusuri melalui makna dan misi Islam itu sendiri. Di mana Islam walaupun dibawa oleh Nabi Muhammad SAW, namun tidak disebut Muhammadanisme, seperti agama Zoroaster yang disandarkan kepada nama pendirinya yaitu Zoroaster (w. 583 SM); atau agama Budha pada Sang Sidharta Budha Gautama; Islam menggambarkan netralitas, universalitas dengan misinya membawa kedamaian bagi seluruh ummat manusia. Jika Islam disebut Muhammadanisme dan Mohammedan, maka penyebutan tersebut secara prinsipil adalah salah, karena mengandung arti Islam sebagai paham Muhammad atau pemujaan terhadap Muhammad SAW. Anologi nama dengan agama lain tidaklah mungkin bagi Islam. Nama Islam mempunyai perbedaan luar biasa dengan agama lain. Kata Islam tidak mempunyai hubungan dengan orang, golongan dan negri tertentu. Islam adalah nama yang diberikan oleh Allah SWT. ${ }^{4}$ sendiri, pada Surat Ali 'Imran ayat 19, yang artinya bahwa sesungguhnya agama yang (diridlai) di sisi Allah hanyalah Islam.

Oleh sebab itu, pluralisme agama yang diartikan bahwa semua agama sama dan semuanya benar, adalah tertolak berdasarkan ayat di atas. Dan itu seharusnya difahami dalam kerangka toleransi beragama, di mana saling menghormati, menghargai sesama pemeluk agama.

Selain itu telah ditegaskan, bahwa ajaran Islam, bukanlah hanya mendatangkan rahmat bagi manusia saja, tetapi lebih dari itu, Islam datang untuk rahmat bagi alam semesta.

4 Abuddin Nata, Studi Islam Komprehensive, (Jakarta: Kencana Prenada Media Group, 2011), hlm. 15-16.

TAHDIS Volume 10 Nomor 1 Tahun 2019 
Allah SWT. berfirman dalam QS. Al-Anbiya/21: 107:

$$
\text { وَمَا أَرْسَنْنَاكَ إلَّال رَمْمَةً لِلْعَالَمِين }
$$

Artinya:

"Dan tidaklah Kami mengutus kamu, melainkan untuk (menjadi) rahmat bagi semesta alam'.

Ulama Tafsir berbeda pendapat mengenai, apakah semua alam yang Muhammad diutus kepada mereka mencakup orang-orang mukmin dan kafir? Atau hanya ahl al-iman (orangorang yang beriman) saja, bukan ahl al-kufr (orang-orang kafir) ? Pendapat yang paling kuat adalah pendapat ibn 'Abbas, bahwasanya Allah mengutus Nabi-Nya Muhammad SAW. rahmat bagi seluruh alam, baik orang-orang mukmin maupun orang-orang kafir.Adapun orang-orang mukmin maka Allah memberi petunjuk kepadanya, memasukkan iman kepadanya, dan mengamalkan dengan apa yang datang dari sisi Allah, sedangkan orang-orang kafir, sesungguhnya dicegah bagi mereka bala' (penderitaan) yang segera diturunkan sebagaimana kepada umat-umat terdahulu yang mendustakan Rasul mereka. ${ }^{5}$

Menurut Pak Quraish Syihab, ayat di atas menyebut empat hal, yaitu: 1. Rasul/utusan Allah; 2. Yang mengutus beliau dalam hal ini Allah; 3. Yang diutus kepada mereka (al'alamin) ; 4. Risalah. Lebih jauh dijelaskan bahwa tidak ditemukan dalam al-Qur'an seorangpun yang dijuluki dengan Rahmat kecuali Rasulullah SAW. dan tidak satupun makhluk yang disifati dengan sifat Allah al-Rahim kecuali Rasululah SAW. Pembentukan kepribadian Nabi Muhammad SAW.

\footnotetext{
${ }^{5}$ Muh\{ammad ibn Jari $<$ r al-T\{abari $<$, Ja $<m i '$ al-Baya $<$ fi $<$ Ta'wi $<$ l alQur'a<n, al-juz\{'u al-tha<Minatah 'ashar, al-t\{ab'ah al-u<la< (T.Tp.:Muassasah al-Risa<lah, 2000) 552.
}

TAHDIS Volume 10 Nomor 1 Tahun 2019 
sehingga menjadikan sikap, ucapan, perbuatan, bahkan seluruh totalitas beliau adalah rahmat, bertujuan mempersamakan totalitas beliau dengan ajaran yang yang beliau sampaikan, karena ajaran beliaupun adalah rahmat menyeluruh, dan dengan demikian menyatu ajaran dan penyampai ajaran, menyatu risalah dan Rasul, dan karena itu pula Rasul SAW. adalah penjelmaan konkret dari akhlak al-Qur'an sebagaimana dilukiskan oleh 'Aisyah r.a. (HR. Ahmad Ibn Hanbal). Kata al'alamin jamak dari kata 'alam, artinya kumpulan sejenis makhluk Allah yang hidup, baik hidup sempurna maupun terbatas. Jadi ada alam manusia, alam malaikat, alam jin, alam hewan dan tumbuh-tumbuhan. Semua itu memperoleh rahmat dengan kehadiran Nabi Muhammad SAW. membawa ajaran Islam. Dengan rahmat itu tepenuhilah hajat batin manusia untuk meraih ketenangan, ketentraman, serta pengakuan atas wujud, hak, bakat dan fitrahnya, sebagaimana terpenuhi pula hajat keluarga kecil dan besar, menyangkut perlindungan, bimbingan dan pengawasan serta saling pengertian dan penghormatan. ${ }^{6}$

Sementara menurut Abuddin Nata, untuk menunjukkan bahwa Islam sebagai pembawa rahmat dapat dilihat dari pengertian Islam itu sendiri. Di mana makna Islam adalah perdamaian, dan orang Muslim adalah orang yang damai dengan Allah dan damai dengan manusia. Damai dengan Allah artinya berserah diri sepenuhnya kepada kehendak-Nya, dan damai dengan manusia bukan saja berarti menyingkir berbuat jahat dan sewenang-wenang kepada sesamanya, melainkan pula ia berbuat baik kepada sesamanya. Dua pengertian ini dinyatakan dalam al-Qur'an al-Karim sebagai inti agama Islam 2002), 519.

6 M. Quraish Syihab, Tafsir al-Misbah, Cet. I (Jakarta: Lentera Hati, TAHDIS Volume 10 Nomor 1 Tahun 2019 
yang sebenarnya. Allah berfirman dalam Q.S. Al-Baqarah [2]: 112:

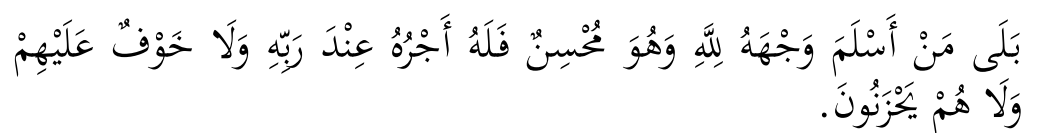

Artinya:

"(Tidak demikian) bahkan barangsiapa yang menyerahkan diri kepada Allah, sedang ia berbuat kebajikan, maka baginya pahala pada sisi Tuhannya dan tidak ada kekhawatiran terhadap mereka dan tidak (pula) mereka bersedih hati." 7

\section{Kesempurnaan Ajaran Islam}

Allah berfirman dalam QS. Al-Maidah/5: 3

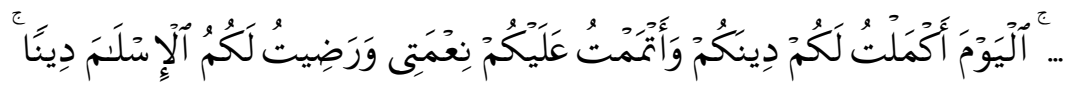

Artinya:

“....Pada hari ini telah kusempunakan untukmu agamamu, dan telah kucukupkan nikmat-Ku kepadamu, dan telah kuridlai Islam itu menjadi agamamu.....".

Maksud pada potongan ayat: "al-yauma akmaltu lakum dinakum" adalah Islam. Dalam hal ini Allah telah mengabarkan kepada Nabi-Nya Muhammad SAW. dan orang-orang beriman bahwasanya Ia telah menyempurnakan bagi meraka al-Iman, maka tak perlu menambahkannya lagi selamanya.

Telah diriwayatkan oleh Muhammad Ibn Husain bahwa ayat ini turun di Arafah, dan tidak turun setelahnya itu hukum halal ataupun haram. Dikatakan bahwa Nabi hidup setelah turunnya ayat ini hanya delapan puluh satu hari saja.

7 Abuddin Nata, Metodologi Studi Islam, Cet. XX (Jakarta: PT Raja Grafindo Persada, 2013), 97-98.

TAHDIS Volume 10 Nomor 1 Tahun 2019 
60 | Universalitas Ajaran Islam

“Waatmamtu 'alaikum ni'mati," menurut Abu Ja'far, maksudnya adalah $\mathrm{Aku}$ telah mencukupkan nikmat-Ku kepadamu wahai orang-orang beriman, dengan kemenanganmu terhadap musuh-Ku dan musuh-musuhmu dari orang-orang musyrik, dan meniadakan mereka dari negaramu, serta memutuskan ketamakan mereka dalam mengembalikan kamu kepada kesyirikan.

"Waraditu lakum al-Islama dina", maksudnya Aku telah meridai ketundukanmu pada perintah-Ku, ketundukan dalam mentaati-Ku, terhadap apa yang Aku syariatkan dari masalah hudud faraid dan mu'amalah. 8

Juga Hadis Nabi SAW. dari Abu Hurairah ra., Rasulullah SAW. bersabda yang artinya:

"Aku tinggalkan dalam kalangan kamu dua perkara yang kamu tidak sekali-kali akan sesat selagi kamu berpegang teguh kepada keduanya, yaitu kitab Allah dan Sunnah Rasulullah (SAW.)". (H.R. Malik). ${ }^{9}$

Pada Hadis ini dapat difahami bahwa peninggalan Nabi SAW kepada ummatnya adalah al-Quran dan Sunnahnya. Dan beliau menegaskan bahwa dengan berpegang teguh (mengamalkannya), tidak akan tersesat (kehilangan arah/tujuan hidup), dengan kata lain, berpegang teguh pada alQur'an dan al-Sunnah, akan mengantarkan ummatnya pada kebahagiaan dunia dan akhirat.

${ }^{8}$ Abi Ja'far Muhammad Ibn Jari>r al-Tabari>, Tafsi $>$ r al-T\}abari>, Mujallad al-Ra>bi'ah, al-T\}ab'ah al-Tha>lithah (Beirut: Da>r al-Kutub al'Ilmiyyah, 1999), 420-421.

${ }^{9}$ Ma>lik Ibn Anas, Muwat\}t\}a' Ma>lik, Kita>b al-Qadr, Ba>b al-Nahy 'an al-Qaul bi al-Qadr,al-Juz'u al-Awwal, (T.Tp.:maktabah al-Taufiqiyyah, T.Th.), 278.

TAHDIS Volume 10 Nomor 1 Tahun 2019 


\section{Perintah agar Melaksanakan Ajaran Islam secara Menyeluruh}

Di samping itu telah dijelaskan dalam al-Qur'an, di mana Allah SWT. berfirman dalam Q.S. Al-Baqarah [2] : 208:

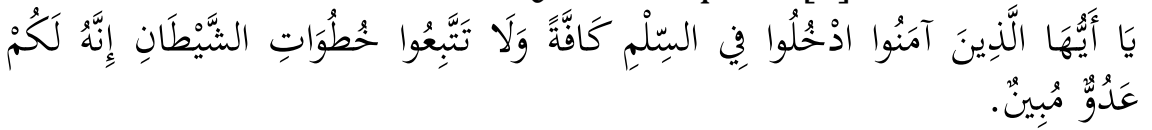

Artinya:

"Wahai orang-orang yang beriman, masuklah kamu semua ke dalam Islam secara menyeluruh, dan janganlah kamu mengikuti langkah-langkah syaitan. Sesungguhnya syaitan itu musuh yang nyata bagimu."

Maksudnya, "Wahai ahl al-kitab yang beriman kepada Musa dan 'Isa, masuklah kalian semua ke dalam (ajaran) Islam dengan Muhammad SAW. secara menyeluruh. Dan makna "Kaffah" di sini adalah menyeluruh. Dan jangan mengikuti jalan (keburukan) yang diserukan oleh syaitan, karena ia musuh yang nyata bagimu." 10

Berkata al-Razi, bahwasanya asal kalimat ini adalah ketundukan. Sesuai dengan firman Allah SWT. Q.S. Al-Baqarah [2]:131:

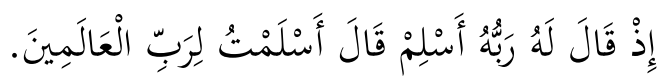

Artinya:

"Ketika Tuhannya berfirman kepadanya: "Tunduk patuhlah!" Ibrahim menjawab:"Aku tunduk patuh kepada Tuhan semesta alam".

Islam diartikan dengan makna seperti itu. Jadi ayat tersebut di atas mempunyai makna: "Masuklah kamu dengan ketundukan dan ketaatan". Yaitu berserah diri kepada Allah,

${ }^{10} \mathrm{Abi}$ 'Abdillah Muhammad ibn Ahmad al-Ans\}ori> al-Qurt\}ubi>, $A l$ Jami' al-Ahka>m al-Qur'a>n, al-Juz'u al-Awwal, al- T\}ab'ah al-Tha>litha, (AlQa>hirah: Da>r al-Kutub al-Mishriyyah, 1935), hlm. 22.

TAHDIS Volume 10 Nomor 1 Tahun 2019 
dan mentaati-Nya dan tidak keluar dari syariat-Nya, dengan menyeluruh. ${ }^{11}$

\section{Sumber Tekstual Keseimbangan Dunia Akhirat.}

Setelah mencermati, dapatlah penulis katakan bahwa Islam mengajarkan proses keseimbangan. Hal ini banyak terlihat, baik dalam ayat-ayat al-Quran, maupun Hadis-hadis Nabi SAW.

Seperti dalam Surat al-Qasas Allah berfirman dalam Q.S. Al-Qashash [28] :77:

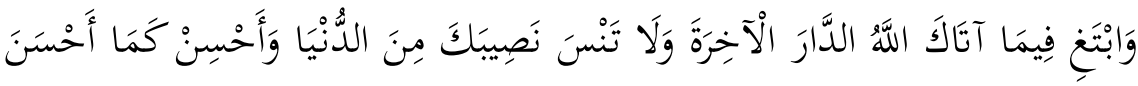

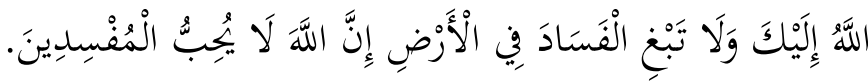

Artinya:

"Dan carilah pada apa yang telah dianugrahkan Allah kepadamu (kebahagiaan) negeri akhirat, dan janganlah kamu melupakan bahagianmu dari (kenikmatan) duniawi....".

Pada zahir ayat ini, membicarakan tentang tempat di akhirat. Maksud ayat: "wabtagi fima ataka Allah al-Dar alAkhirah", adalah belanja kanlah hartamu yang membawa kepada surga dan bersikap rendah hatilah! Sementara Kalimat: "Wala tansa nasibaka min al-Dunya", maksudnya adalah infak pada ketaatan terhadap Allah, adalah bagian (hak) seseorang di dunia, selain dari apa yang dia makan dan minum; atau Ketika Allah memerintahkan membelanjakan harta untuk akhirat Allah menjelaskan dengan kalimat ini bahwa tidak mengapa menikmatinya (sebagian hartanya) secara wajar. ${ }^{12}$

11 Muhammad Jama $>$ l al-Di>n al-Qa $>\operatorname{simi}>$, Tafsi $>$ r al-Qa $>\operatorname{simi}>$, almujallad al-Tha>niyah, (Beirut: Da>r al-Kutub al-'Ilmiyyah, 1997), 86.

12 Muhammad al-Ra>zi> Fakhr , Tafsi $>r$ Al-Fakhr al-Ra>zi>, alMujallad al-Ta>si', (T.Tp. :Da>r al-Fikr, 2005), 523.

TAHDIS Volume 10 Nomor 1 Tahun 2019 
Allah berfirman dalam Q.S. Al-Jumu'ah [62]: 9-11:

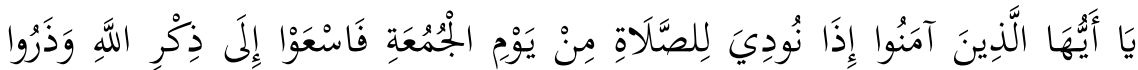

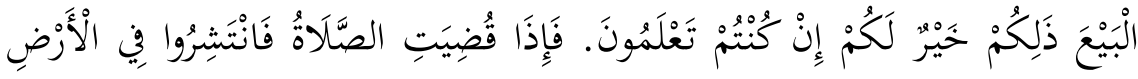

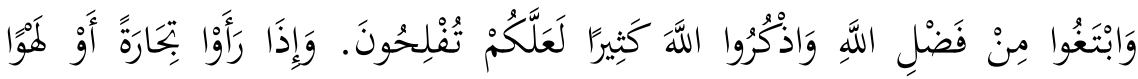

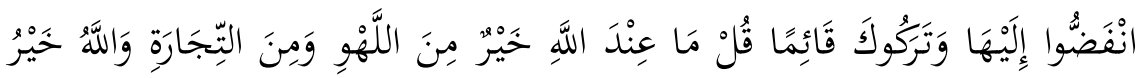

الرَّزِقِِنَ.

Artinya:

"Wahai orang-orang beriman! Apabila telah diseru untuk melaksanakan shalat pada hari Kum'at, maka segeralah kamu mengingat Allah dan tinggalkanlah jual beli. Yang demikian itu lebih baik bagimu jika kamu mengetahui. Apabila shalat dilaksanakan, maka bertebaranlah kamu di bumi; carilah karunia Allah dan ingatlah Allah banyakbanyak agar kamu beruntung.Dan apabila mereka melihat perniagaan atau permainan, mereka bubar untuk menuju kepadanya dan mereka tinggalkan kamu sedang berdiri (berkhotbah). Katakanlah: "Apa yang di sisi Allah lebih baik daripada permainan dan perniagaan", dan Allah Sebaik-baik Pemberi rezki."

Hadis-hadis Nabi juga banyak berbicara tentang dunia dan akhirat. Di mana dalam suatu Hadis yang artinya:

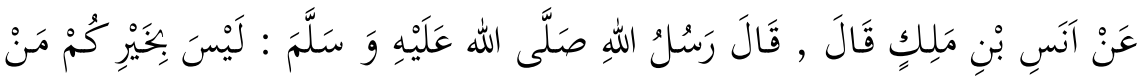

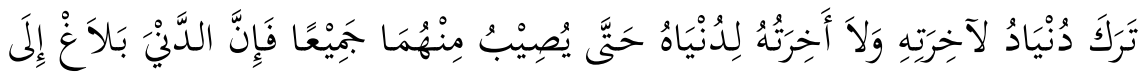

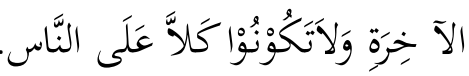

Artinya:

"Bukanlah orang yang baik di antara kamu orang yang meninggalkan kepentingan dunia untuk mengejar akhirat atau meninggalkan akhirat untuk mengejar dunia sehingga dapat memadukan keduanya. Sesungguhnya kehidupan dunia mengantarkan kamu menuju kehidupan

TAHDIS Volume 10 Nomor 1 Tahun 2019 
akhirat. Janganlah kamu menjadi beban orang lain". (H.R. Ibnu Asakir al-Dailami).13

Juga Hadis Abdullah Ibn 'Amr Ibn Ash, bahwa Rasul bersabda yang artinya:

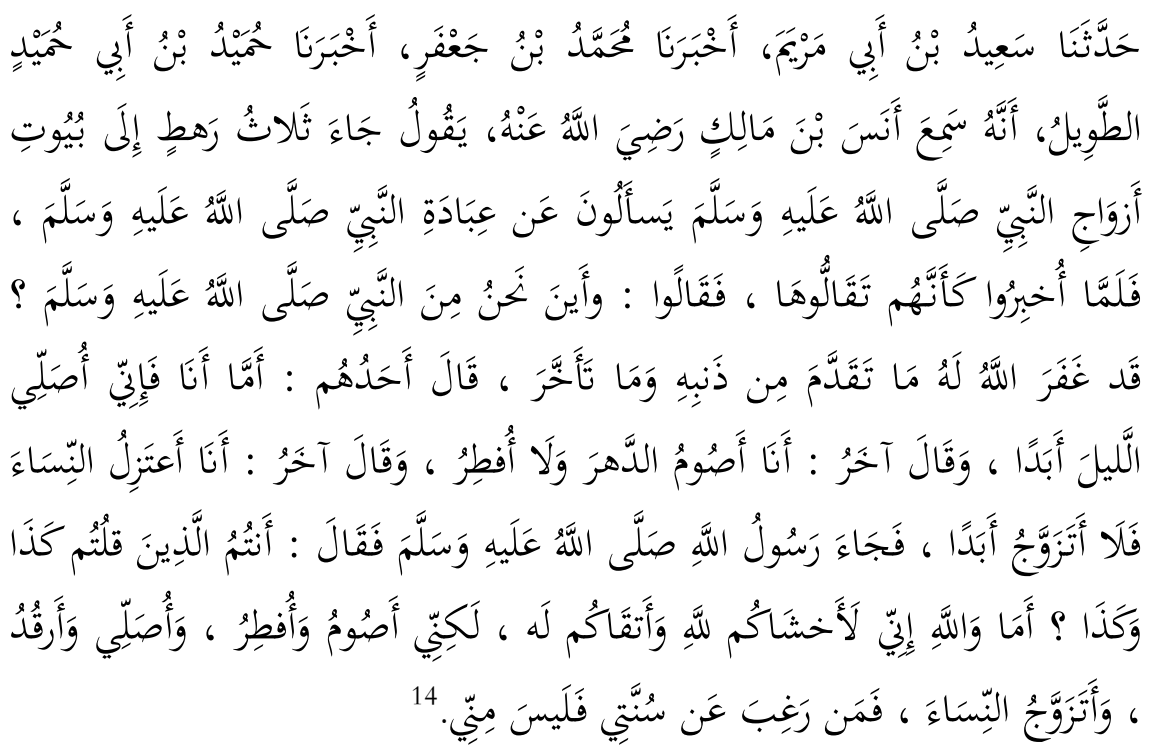

Artinya:

Sa'id ibn Abi Maryam telah menceritakan kepada kami, Muhammad ibn Ja'far telah mengabai kami, Humaid ibn Abi Humaid al-Tawil telah mengabari kami, bahwasanya ia telah mendengar Anas ibn Malik RA. berkta: "Datang tiga orang ke rumah istri-istri Nabi SAW., mereka bertanya tentang ibadah Nabi SAW. Takkala mereka diberitahu, seakan-akan mereka merasa remeh, lalu

${ }^{13} \mathrm{Al}-\mathrm{Tirmizi}>$, Jam'u al-Jawa>mi', au al-Ja $>m i$ ' al-Kabi $>r, B a>b$ harf al-La>m, al-Juz'u al-Awwal, Hadis No. 17282.

${ }^{14}$ Muh\{ammad ibn Isma $<$ 'i $<$ l al-Bukha $<$ ri $<, S\{a h\{i<h\{$ al-Bukha $<r r i<$, al-juz\{'u al-sa<bi', ba<b targhi<b fi< al-Nika<h\{, al-t\{ab'ah al-u<la< (T.Tp.:Da<r T\{auq al-Naja<h, 1422H) 2; Muslim ibn al-Hajja<j al-Qushairi< al-Naisa<buri<, $S\{a h\{i<h\{$ Muslim, al-juz\{'u al-tha<ni<, ba<b istih\{ba<b alnika $<$ h liman ta<qat nafsahu (Beiru<t:Da<r Ih\{ya<' al-Tura<th al-'Arabi, T.Th.) <1020; Abu< 'Abd al-Rah\{ma<n Ah\{mad ibn Shu'aib al-Nasa $<\mathrm{i}<$, Sunan al-Nasa<i<, al-juz\{'u al-sa<dis, ba<b al-nahy 'an al-tabattal, (HT.Tp.:Maktab al-Mat\{bu<'a<t al-Isla<mi<yah, 1986) 60.

TAHDIS Volume 10 Nomor 1 Tahun 2019 
mengatakan, "Dimana kita dari (ibadahnya) Nabi SAW.? Sungguh beliau telah diampuni oleh Allah dosa yang lalu maupun yang akan datang. Salah satu di antara mereka mengatakan, "Adapun saya, saya akan shalat malam selamanya." Yang lainnya berkata, "Saya akan berpuasa selamanya dan tidak berbuka." Dan lainnya mengatakan, "Saya akan menjauhi wanita dan tidak menikah selamanya." Maka datanglah Rasulullah SAW. dan bersabda, "Apakah anda semua yang mengatakan ini dan itu? 'Demi Allah, sesungguhnya saya adalah yang paling takut kepada Alah dan paling bertakwa kepadaNya. Akan tetapi saya berpuasa dan berbuka, saya shalat (malam) dan beristirahat dan saya menikahi wanita. Siapa yang tidak menyukai sunahku (kebiasaanku), maka dia bukan dari (golongan)ku." (HR. Bukhari dan Muslim).

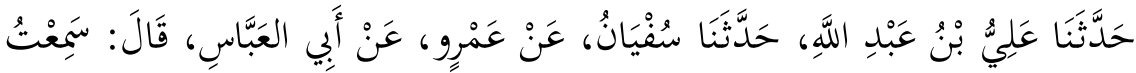

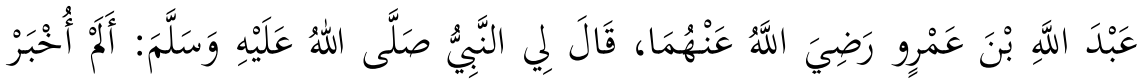

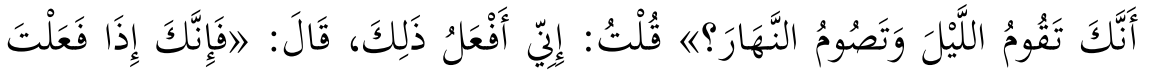

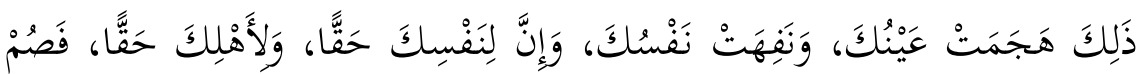

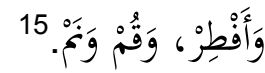

Artinya:

"'Ali ibn 'Abd Allah telah menceritakan kepadaku, Sufyan telah menceritakan kepadaku, dari 'Amr dari Abi al'Abbas, ia berkata: Saya telah mendengar 'Abd Allah ibn 'Amru RA., berkata kepadaku Nabi SAW., "Bukankah telah dikabarkan kepadaku bahwasanya engkau

${ }^{15}$ Bukha $<\mathrm{ri}<, S\{a h\{i<h\{$ Bukha $<$ ri, $<$ al-juz\{'u al-tha<ni<, $b a>b \quad m a<$ yakrah man taraka qiya $<m$ al-lail liman ka<na yaqumuhu, 54; Muslim, $S\{a h\{i<h\{$ Muslim, al-juz\{'u al-tha<ni<, ba<b al-nahy 'an s\{aum al-dahr liman tad\{arrar, 812; Al-Nasa $<i<$, Sunan al-Nasa $<i<$,, al-juz\{'u al-ra<bi', ba $>b$ s\{aum yaum wa ift $\{a<r$ yaum wa dhikr ikhtila $<f$ al-fa $<z\{$, 211; $\mathrm{Abu}<\mathrm{Da}<\mathrm{wu}<\mathrm{d}$ Sulaima $<$ n ibn al-Ash'at, Sunan Abi< Dawud, al-juz\{'u al-tha<ni<, ba<b ma< yu'mar bihi min al-qas\{d fi< al-s\{ala<h (Beiru<t:al-Maktab al-'As\{ri<yah, T.Th.) 48.

TAHDIS Volume 10 Nomor 1 Tahun 2019 
berpuasa dan tidak pernah berbuka, serta engkau sholat dan tidak pernah tidur? Berpuasalah dan berbukalah serta sholatlah dan tidurlah. Sesungguhnya bagi tubuhmu ada haq atasmu. Sesungguhnya bagi kedua matamu ada hak atasmu, dan sesungguhnya bagi istrimu ada hak atasmu".16 (H.R. Bukhori, Muslim, Abu Dawud dan Nasai).

Hadis tersebut di atas, menyangkut kisah sahabat Abdullah bin 'Amr yang berpuasa setiap hari dan salat sepanjang malam hingga berita tentangnya sampai kepada Nabi yang kemudian Nabi mengeluarkan Hadis tersebut. Kemudian ada lagi kisah tentang Abu Darda' dan Salman yang diriwayatkan oleh Abu Juhaifah. Hadis ini senada dengan hadis tersebut. Namun di dalam Hadis itu terdapat perkataan Salman

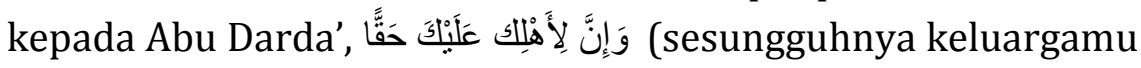
[istrimu] memiliki hak atas kamu) lalu nabi SAW menyetujuinya dalam hal tersebut. Kemudian terdapat lafal بَََْ (telah sampai [kabar] kepada nabi SAW bahwa aku berpuasa terus menerus). Sebagaimana yang telah disebutkan bahwa orang yang menyampaikan berita itu kepada nabi SAW adalah Amr bin Al-Ash. Sedangkan Imam Muslim dalam hadis lain meriwayatkan dengan redaksi عَلَّنَ حَظًَّ (ada bagian atasmu). Kemudian dalam riwayat al Ismaili

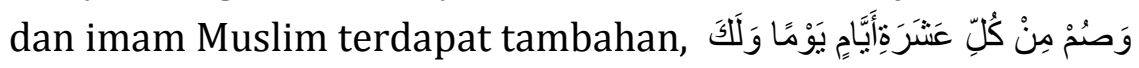

16Bukhari, S\}ah\}ih\} Bukhari, Ba>b Haq al-Ahl fi> al-S\}aum, ; Abi alHusain Muslim Ibn al-Hajja $>$ j, S\}ah\}ih\} Muslim, Kita $>b$ al-S\}iya $>m, B a>b$ alNahy 'an S>\}aum al-Dahr liman tad\}arrara bih, Hadis no 186, al-T\}ab'ah alTha>niyah, (Beirut: Da>r al-Kutub al-'Ilmiyyah, 2003), 420; Jala $>1$ al-Di $>\mathrm{n}$ alSayu $>\mathrm{t}\} \mathrm{i}>$, Sunan al-Nasa>i>, Kita $>b$ al-S\}iya $>m$, Ba $>b$ S\}aum 'asyrah Ayya $>m$ min al-Syahr, al-Mujallad al-Tha>ni>, (Beirut: Da>r al-Kutub al-'Ilmiyyah, T.Th.), 213.

TAHDIS Volume 10 Nomor 1 Tahun 2019 
أجْرُ (berpuasalah sehari dalam setiap sepuluh hari dan bagimu pahala 9 hari). ${ }^{17}$

Jelas dari pemaparan ayat-ayat al-Qur'an dan Hadishadis Nabi SAW. di atas, mengajarkan kepada kita, bahwa Islam tidak membenarkan kita beribadah semata untuk tujuan akhirat dengan melupakan kehidupan kita di dunia atau sibuk dengan urusan dunia, sehingga melupakan urusan akhirat sebagai akhir tujuan hidup kita. Namun Islam mengajarkan keseimbangan dari keduanya. Ini sekaligus membuktikan bahwa ajaran Islam adalah ajaran yang syamil.

Di samping ini terdapat Hadis- hadis lain yang membicarakan tentang konsep keseimbangan dalam bidang yang lain, seperti:

A. Konsep Keseimbangan dalam Bentuk Kepedulian Lingkungan, Sosial, dan Fauna.

Dalam Hadis-hadis Nabi khususnya, mengajarkan kepedulian dalam konsep syamil (menyeluruh).

1. Hadis-hadis Nabi SAW. yang berbicara tentang kepedulian sosial

Hadis yang diriwayatkan dari 'Abdullah RA. Rasulullah SAW. bersabda yang artinya:

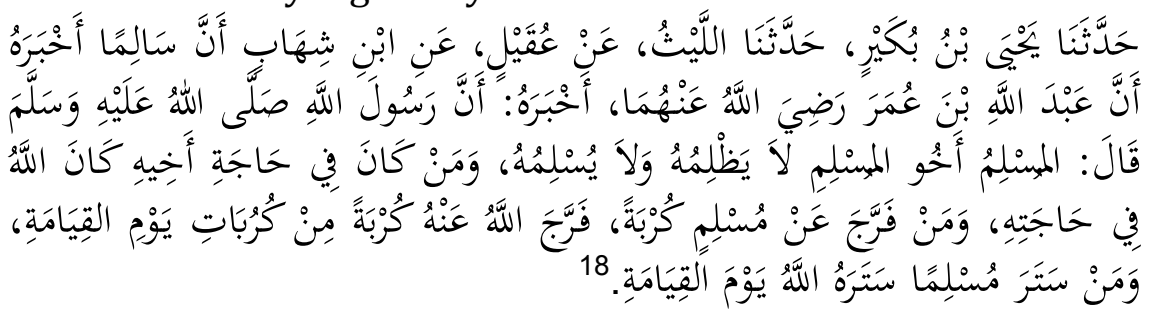

17 http://deden11410217.blogspot.com/2013/05/keseimbangandunia-akhirat.html. Diakses pada tanggal 09, Juni 2014.

${ }^{18}$ Bukha $<\mathrm{ri}<, S\{a h\{i<h\{$ Bukha $<<r i<$, al-juz\{'u al-tha<lith, $b a<b$ la $<a$ yaz\{lim al-muslim wala< yaslimuhu, 128; Muslim, $S\{a h\{i<h\{$ Muslim, al-juz\{'u al-ra<bi', ba>b tah\{ri<m al-z\{ulm, 1996; Abu< Da<wud, Sunan Abu<Da<wud,

TAHDIS Volume 10 Nomor 1 Tahun 2019 
Artinya:

“Orang Islam itu saudara orang Islam lainnya, maka janganlah menganiaya, dan tidak boleh ia membiarkannya (kepada yang membahayakan). Barangsiapa yang menolong keperluannya, maka Allah menolong apa yang menjadi keperluannya. Dan barangsiapa yang memudahkan (memberi jalan keluar) dari kesulitannya, maka Allah akan memudahkan dari kesulitannya di hari kiamat. Dan barangsiapa yang menutupi (aib) orang Islam, maka Allah akan menutupinya di hari kiamat." 19 (H.R. Bukhari, Muslim, Abu Dawud, dan Turmudzi).

Konsep kepedulian Sosial, juga tidak terbatas pada sesama Muslim, seperti Hadis yang membicarakan tentang berbuat baik pada tetangga, yang artinya:

Dari Abi Hurairah r.a. dia berkata: Rasulullah SAW. bersabda: "Barangsiapa beriman kepada Allah dan kepada hari akhir, maka hendaknya dia menghormati ttamunya, barangsiapa beriman kepada Allah dan kepada akhir, maka hendaknya dia berlaku baik kepada tetangganya, dan barangsiapa beriman

al-juz\{'u al-ra<bi', ba>b al-Mua<khah, 273; Muh\{ammad ibn 'I $<$ ssaa $<$ alTirmi $<$ dhi $<$, Sunan al-Tirmidhi<, al-juz\{'u al-ra<bi', ba>b ma<ja<'a fi< al-str 'ala< al-muslim, 34.

${ }^{19} \mathrm{Ahmad}$ Ibn 'Ali> Ibn Hajar al-'asqala>ni>, Fath al-Ba>ri bisyarh sahih al-Bukha>ri>, Kita>b al-Maza>lim, Ba>b La> yuzlimu Muslim wala> yuslimuhu, Hadis no. 2442, ( al-Qa $>$ hirah: Da $>$ r al-Diya $>$ n li al-Tura $>$ th, 1986), 116; Abi> al-Husain Muslim Ibn Al-Hajja $>$ j, S\}ah\}i $>h\}$ Muslim, Kita $>b$ al-Birr wa al-S\}ilah wa al-Adab, Ba>b tah\}ri>m al-Zulm, al-T\}ab'ah alTha $>$ niyah, (Beirut: Da>r al-Kutub, 2003), 1000; Abu Daud, Sunan Abi Daud, Kita>b al-Adab, Ba>b al-Mua>kha>h, al-Juz'u al-Tha>lith, al-T\}ab'ah alAwwal, (Beirut: Da>r al-Kutub al-'Ilmiyyah, 1996), 278-279; Abi 'I $>$ sa> Muhammad Ibn 'I $>$ sa> Ibn Saurah al-Tirmizi>, Al-Ja>mi' al-S\}ah\}i>h\} wa huwa Sunan al-Tirmidzi, Kita $>b$ al-Birr wa al-S\{ilah, Ba>b al-satr 'ala alMuslim, al-Juz'u al-Tha>lith, al-T\}ab'ah al-U>la, (Beirut: Da>r al-Kutub al'Ilmiyyah, 2000), 77.

TAHDIS Volume 10 Nomor 1 Tahun 2019 
kepada Allah dan hari akhir, maka hendaknya dia berkata yang baik atau diam." (H.R. Muslim).

Dari Hadis ini dapat difahami, bahwa Islam tidak menganggap cukup keimanan kita dengan hanya beriman kepada Allah dan Rasul-Nya, namun Islam juga menuntut kita untuk mengaplikasikan keimanan kita ke dalam bentuk nyata, seperti berbuat baik pada tetangga, tamu, juga berkata baik atau diam (jika tidak mampu berkata baik).

Sebagaimana yang kita ketahui banyak dari ayat-ayat alQur-an, di mana kata iman, selalu digandengkan dengan kata amal shaleh. Seperti Firman Allah SWT. dalam Q.S. Al-Ashr [103]: 2-3:

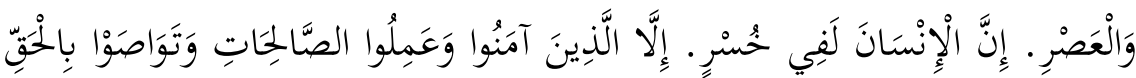
وَتَوَاصَوْار بِالصَّنَّرُ.

Artinya:

"Demi masa. Sungguh, manusia berada dalam kerugian, kecuali orang-orang yang beriman dan mengerjakan kebajikan seta saling menasihati untuk kebenaran dan saling menasihati untuk kesabaran."

Juga firman Allah dalam Q.S. Al-Baqarah [2]: 177:

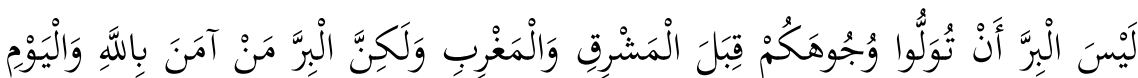

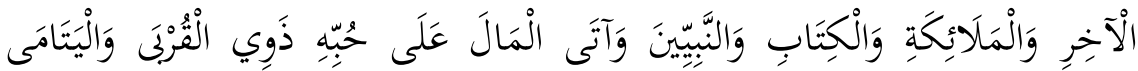

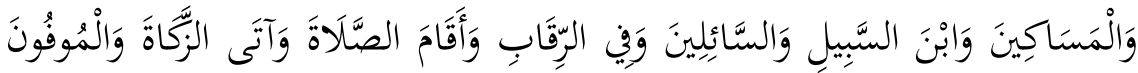

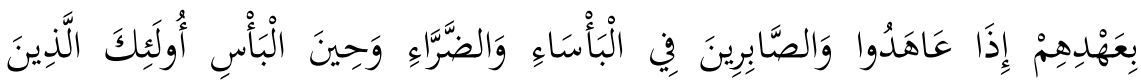

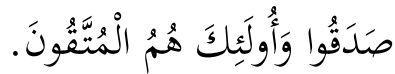


Artinya:

"Kebajikan itu bukanlah menghadapkan wajahmu ke arah Timur dan ke Barat, tetapi kebajikan itu ialah (kebajikan) orang yang beriman kepada Allah, hari akhir, malaikat-malaikat, kitab-kitab, dan Nabi-nabi dan memberikan harta yang dicintainya kepada kerabat, anak yatim, orang-orang miskin, orang-orang yang dalam perjalanan (musafir), peminta-minta, dan untuk memerdekakan hamba sahaya, yang melaksanakan shalat dan menunaikan zakat, orang-orang yang menepati janji apabila ia berjanji, dan orang yang sabar dalam kemelaratan, penderitaan dan pada masa peperangan. Mereka itulah orang-orang yang benar, dan mereka itulah orang-orang yang bertaqwa." ().

Demikianlah, bahwa iman seseorang tidaklah sempurna sebelum melakukan amal kebajikan. Dan amal kebajikan merupakan bukti dari keimanan seseorang.

Hadis tentang kepedulian sosial di atas, juga sejalan dengan firman Allah SWT dalam Q.S. Al-Nisa [4]:36.:

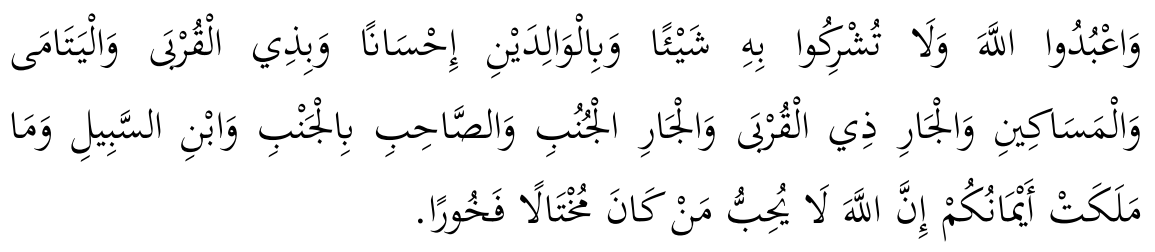

Artinya:

"Sembahlah Allah (beribadah kepada Allah dan jangan menyekutukan-Nya dengan sesuatu apapun. Dan terhadap kedua orang tua hendaklah berbakti (membantu) family, serta kerabat dan anak yatim dan orang-orang miskin dan tetangga yang family dan tetangga yang bukan family, teman bepergian dan orang merantau dan demikian pula terhadap budak sahayamu". 
2. Hadis-hadis Nabi SAW. yang Berbicara tentang Kepedulian Lingkungan

a. Hadis yang diriwayatkan oleh Abu Hurairah RA., Rasulullah SAW. bersabda yang artinya:

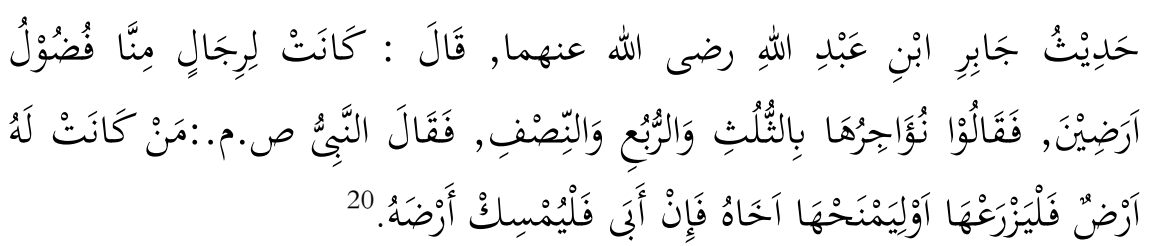

Artinya:

"Hadist Jabir bin Abdullah RA. dia berkata : Ada beberapa orang dari kami mempunyai simpanan tanah. Lalu mereka berkata: Kami akan sewakan tanah itu (untuk mengelolahnya) dengan sepertiga hasilnya, seperempat dan seperdua. Rosulullah SAW. bersabda: "Barangsiapa yang memiliki tanah, maka sebaiknya menanaminya atau memberikan saudaranya lalu apabila ia enggan, maka sebaiknya ia memelihara tanah itu. ${ }^{21}$ (H.R. Bukhari, Muslim, Abu Daud,Nasai, ibn Majah dan Ibn Hibban).

${ }^{20}$ Bukha $<$ ri $<, \quad S\{a h\{i<h\{$ Bukha<ri, al-juz\{'u al-tha<lith, ba<b ma< $k a<$ na min as $\{h\{a<b$ al-Nabi< SAW>., 107; Hadis ini diriwayatkan bi almakna oleh: Muslim, $S\{a h\{i<h\{$ Muslim, al-juz\{'u al-tha>lith, ba<b kara<' alard\{, 1177; Abu< Da<wud, Sunan Abu<Da<wud, al-juz\{\{'u al-tha<lith, $b a<b$ fi< al-tashdi<d fi< dha<lik, 259; Al-Nasa $<i<$, Sunan al-Nasa $<i<$, al-juz\{'u al$s a<b i$ ', $b a<b$ dhikr al-ah\{a<dith al-mukhtalifah fi< al-nahy 'an kara<', 33; Ibn Ma<jah, Sunan ibn Ma<jah, al-juz\{'u al-tha<ni<, ba<b al-muza<ra'ah bi althuluth wa al-rubu', (T.Tp.:Da<r Ih\{ya<; al-Kutub al-'Arabi<yah, T.Th.) 820; Muh\{ammad ibn $\mathrm{H}\{\mathrm{ibba}<\mathrm{n}$ ibn $\mathrm{Ah}\{$ mad ibn $\mathrm{H}\{\mathrm{ibba}<\mathrm{n}, \quad S\{a h\{i<h\{i b n$ $H\left\{i b b a<n, a l-j u z\left\{{ }^{\prime} u\right.\right.$ al-h\{a<diyatah 'asharatah, ba<b dhikir khabar qad yu<ham ghair mutabah\{r fi< $\quad s\{a n a<' a h, \quad a l-t\{a b ' a h \quad a l-u<l a<$ (Beiru<t:Muassasah al-Risa<lah, 1988) 549.

${ }^{21}$ Ahmad Ibn 'Ali> Ibn Hajar al-'asqala>ni>, Fath al-Ba>ri bisyarh sahih al-Bukha>ri>, Kita>b al-Maza>lim, Ba>b La> yuzlimu Muslim wala> yuslimuhu, Hadis No. 2341 (al-Qa>hirah: Da>r al-Diya>n li al-Tura>th, 1986), 28: Diriwayatkan dengan makna yg serupa oleh : Abi> al-Husain Muslim alHajjaj>j, S\}ahi>h\} Muslim, Kita>b al-Buyu>', Ba>b Kira>u al-Ard\}, al-T\}ab'ah al-Tha>niyah (Beirut: Da>r al-Kutub al-'Ilmiyyah, 2003), 597. Jala $>\mathrm{l}$ al-Di $>\mathrm{n}$

TAHDIS Volume 10 Nomor 1 Tahun 2019 
Memelihara dan memanfaatkan lahan atau tanah dianjurkan dalam Islam. Dalam Hadis di atas difahami, agar tanah atau lahan dimanfaatkan dengan baik, seperti ditanami dengan tumbuh-tumbuhan, dan tidak diterlantarkan begitu saja. Bila si pemilik tidak mampu melakukannya, hendaklah memberikannya kepada saudaranya untuk dikelola. Karena tanaman bila sudah panen, atau berbuah, pasti akan akan menguntungkan bagi pemiliknya.

b. Hadis riwayat Abu Hurairah r.a. dari Rasulullah SAW., beliau bersabda:

Janganlah engkau kencing di air yang tergenang yang tidak mengalir, kemudian engkau mandi di dalamnya".22(Hadis Bukhari dan Muslim).

c. Masih Hadis Abu Hurairah, bahwasanya Nabi SAW bersabda:

"Waspadailah perbuatan-perbuatan yang bisa mendatangkan laknat : Buang air di sumber mata air,

al-Sayu $>$ t\}i, Sunan Nasai bi syarh al-Ha $>$ fiz Jala $>l$ al-Di $>n$ al-Sayu $>t\} I$, Kitab $>$ al-Muza>ra'ah, al-Juz'u al-Ra>bi'ah, (Beirut: Da>r al-Kutub al-'Ilmiyyah, T.Th.), 36-37; Abi $>$ Da $>$ wud Sulaima $>$ n Ibn al-Asy'at, Sunan Abu Daud, Ba>b Tasydi $>d$ fi $>$ za>lik, al-Juz'u al-Tha>ni>, al-T\}ab'ah al-U>>>la, (Beirut: Da>r al-Kutub al-'Ilmiyyah, 1996), 466.

22 Mu>sa Sya>hi>n, Taysi>r s\}ah\}i>h\} al-Bukha>ri>, Kita>b alWud\} $u>$ ', Ba>b al-Baul fi> alma >' al-Da>im, al-Juz'u al-Awwal, Al-T\}ab'ah alU>la $>$, (Al-Qa>hirah: Maktabah al-Syuru>q al-Dauliyyah,2003), 118. Lihat juga: Abi $>$ al-Husain Muslim Ibn Hajjaj>, S\}ah\}i>h\} Muslim, Kita>b alT\}aha $>$ rah, Ba>b al-Nahy 'an al-Baul fi> al-Ma>' al-Ra>kid, al-T\}ab'ah alTha>niyah, (Beirut: Da>r al-Kutub al-'Ilmiyyah, 2003), 122. Abu Da>wud, Sunan Abi> Da>wud, Kita>b al-T\}aharah, Ba>b al-Baul fi $>a l-M a>^{\prime} a l-R a>k i d$, ( Beirut: Da>r al-Kutub al-'Imiyyah, 1996), 58.

TAHDIS Volume 10 Nomor 1 Tahun 2019 
tengah jalan, dan naungan (manusia)".23 (H.R. Abu Dawud)

Dari Hadis-hadis ini, jelas Islam sangat peduli akan lingkungan dan kemashlahatan orang banyak. Buang air pada sumber mata air, jelas akan mencemari sumber air tersebut. Mencemari sumber air, artinya memasukkan bakteri-bakteri atau kuman-kuman pada air tersebut. Sehingga tidak mustahil jika air itu digunakan, dapat membawa mudharat bagi pemakainya.Belum lagi air tersebut akan tercampur dengan najis, sehingga bila sudah merusak bau rasa dan warnanya, maka air tersebut sudah terkena najis, dan tidak sah dipakai untuk bersuci. Demikian juga buang air di tengah jalan atau naungan manusia, akan membuat masyarakat umum menjadi terganggu.

Tidak hanya itu, menebang pohon pun tanpa alasan yang benar, sesuatu yang dilarang di dalam ajaran agama kita.

d. Hadis Abu Dawud

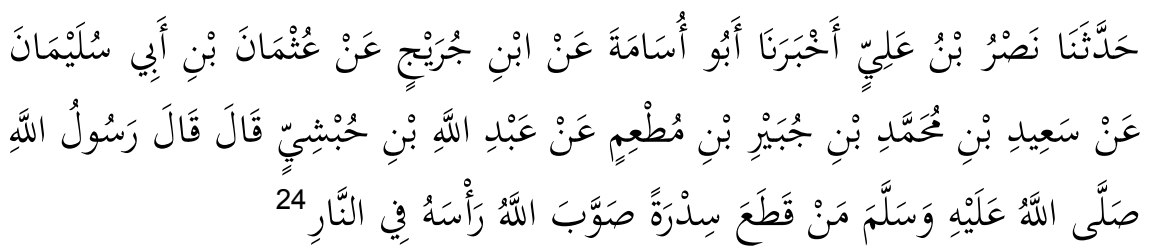

Artinya:

Nasr ibn 'Ali telah menceritakan kepada kami, Abu Usamah telah mengabari kami, dari ibn Juraij dari 'Uthman ibn Abi Sulaiman dari Sa'id ibn Muhammad ibn Jubair ibn Mut'im dari 'Abd Allah ibn Hubshi berkata,

${ }^{23} \mathrm{Abi}>$ Dawud, Sunan Abi> Dawud, Kita>b al-T\}aharah, Ba>b alMawa>di' allati> naha> al-Nabi SAW. 'an al-baul fi>ha>, al-Juz'u al-Awwal, al-T\}ab'ah al-U>la>, (Beirut: Da>r al-Kutub al-'Ilmiyyah, 1996), 47.

${ }^{24} \mathrm{Abu}<\mathrm{Da}<\mathrm{wud}$, Sunan Abi< Da<wud, al-juz\{'u al-ra<bi', ba<b $\mathrm{fi}<$ qat\{' $i<$ al-sadr, 361.

TAHDIS Volume 10 Nomor 1 Tahun 2019 
Rasulullah SAW. bersabda: "Barangsiapa menebang pohon bidara maka Allah akan membenamkan kepalanya dalam api neraka." (HR. Abu Dawud)

Abu Dawud pernah ditanya tentang Hadis tersebut, lalu ia menjawab, "Hadis ini singkat, makna hadits ini adalah bahwa barangsiapa menebang pohon bidara di padang bidara dengan sia-sia dan zhalim; padahal itu adalah tempat untuk berteduh para musafir dan hewan-hewan ternak, maka Allah akan membenamkan kepalanya di neraka. ${ }^{25 "}$

Dari Hadis ini, dijelaskan ancaman bagi orang yang menebang pohon tentu tanpa alasan yang benar. Walaupun tekstual Hadis tersebut hanya disebutkan pohon bidara, namun maksudnya adalah umum, yakni semua pohon. Karena mengingat pentingnya pepohonan dalam menjaga keseimbangan alam ini. Pepohonan bukan saja untuk mencegah banjir, longsor, untuk memberikan keteduhan, keindahan, juga untuk mencegah terjadinya global warming. Global warming yang terjadi di dunia dewasa ini, karena antara lain banyaknya penebangan pohon, pengudulan hutan, dan lain sebagainya.

Selain Hadis yang melarang kita menebang pohon tanpa alasan yang bena, juga terdapat Hadis yang secara tidak langsung menganjurkan kita menanam tumbuh-tumbuhan. Seperti Hadis Anas bin Malik r.a., Nabi SAW. bersabda yang artinya:

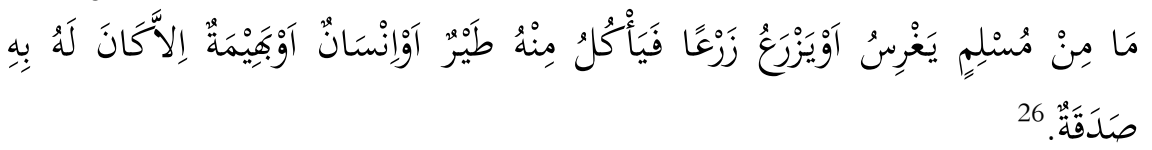

${ }^{25} \mathrm{Abu}<\mathrm{Da}<$ wud, Sunan Abi< Da<wud, al-juz\{'u al-ra<bi', ba<b fi< qat $\left\{\right.$ ' $^{\prime}<a l$-sadr, 361.

${ }^{26}$ Bukha $<$ ri $<, S\{a h\{i<h\{$ Bukha $<r i<$, al-juz\{'u al-tha<lith, $b a<b$ fad $\{l$ alz\{ar'I wa al-ghars idha $<$ akala minhu, 103; Muslim, $S\{a h\{i<h\{$ Muslim, aljuz\{'u al-tha<lith, ba<b fad\{l al-ghars wa al-z\{ar', 1189.

TAHDIS Volume 10 Nomor 1 Tahun 2019 
Artinya:

"Tidak seorang Muslim yang bercocok tanam atau bertani, lalu sebagiannya dimakan burung atau dicuri orang atau dimakan ternak, kecuali itu sebagai shadaqahnya". (H.R. Bukhari Muslim).

Hadis ini pada dasarnya menjelaskan dua hal, pertama, menanam tumbuh-tumbuhan; Kedua, buah yang dimakan oleh binatang dari tanaman yang kita tanam, akan bernilai sedekah. Kata sadaqah yang dimaksudkan di sini adalah pahala dan kebaikan-kebaikan. ${ }^{27}$

\section{Hadis-hadis Nabi SAW. yang Berbicara tentang Kepedulian Binatang}

a. Hadis Shadad ibn 'Aus:

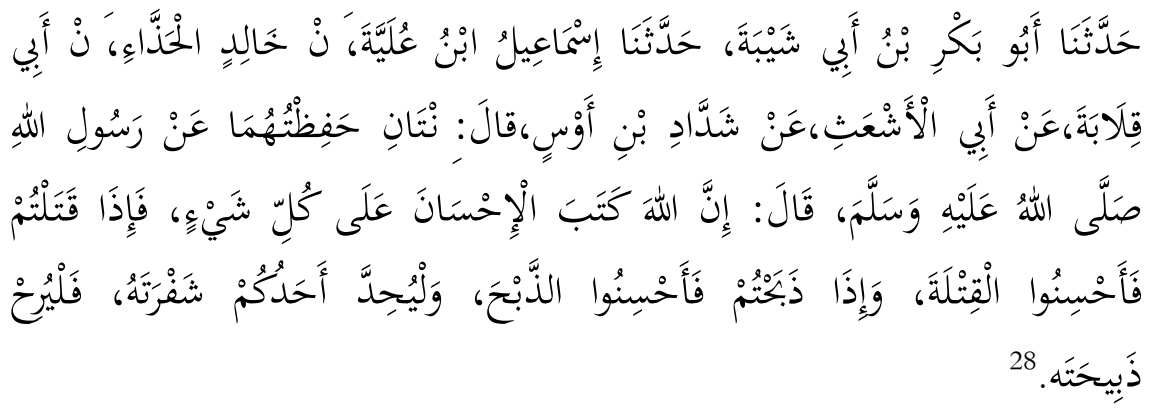

Artinya:

Rasulullah saw bersabda: "Sesungguhnya Allah mewajibkan berlaku baik terhadap segala sesuatu. Jika kamu membunuh hendaknya membunuh dengan cara yang baik, dan jika kamu menyembelih maka sembelihlah dengan cara yang baik, hendaknya dia menajamkan pisau dan menyenangkan hewan

${ }^{27}$ Mus\}tafa Muhammad 'Amrah, Jaudahir al-Bukha>ri wa Syarh alQast\}ala $>n i>$, Kita $>b$ al-Muza $>r a ' a h, B a>b$ Fad\}l al-Zar'u wa al-Gars, ( T.Tp.: Da>ral-Fikr, 1994), 159.

${ }^{28}$ Muslim, $\mathrm{S}\{\mathrm{ah}\{\mathrm{i}<\mathrm{h}\{$ Muslim, al-juz\{'u al-tha $<$ lith, ba $<\mathrm{b}$ al-amr bi ah $\{\mathrm{sa}<\mathrm{n}$ al-adhabh [

TAHDIS Volume 10 Nomor 1 Tahun 2019 
sembelihan itu." 29 (H.R. Muslim, Abu Dawud, Nasai, Tirmizi, dan Ibn Majah).

b. Hadis Ibnu Abbas r.a, yang artinya:

"Rasulullah SAW. melewati seorang lelaki yang meletakkan kakinya di muka seekor kambing, sementara dia sedang mengasah pedangnya. Kambing tersebut melihat ke arahnya dengan kedua matanya. Maka Rasulullah saw berkata: "Apakah kamu ingin membunuhnya dua kali? Mengapa tidak kamu asah dahulu pedangmu sebelum kamu baringkan kambing itu?"30 (H.R. Hakim)

c. Hadis Suhail bin al-Handhalah RA. yang artinya:

"Rasulullah SAW. pernah melewati seekor unta yang punggungnya telah bertaut dengan perutya. Baginda bersabda: "Bertakwalah kepada Allah terhadap binatang ternakan yang tidak dapat berkata-kata ini. Naikilah dia dengan cara yang baik dan makanlah dagingnya dengan cara yang baik (pula)."31 (H.R.Abu Daud, dihasankan sanadnya oleh al-Arnauth).

\footnotetext{
${ }^{29} \mathrm{Abi}>$ al-Husein Muslim al-Hajjaj>j, S\}ah\}i>h\} Muslim, Kita>b alS\{ayd wa al-zaba>hah wa ma> ya'kulu min al-Hayawa>n, Ba>b al-Amr bi Ihsa>n al-zabh wa al-qatl wa tahdi>d, 777-778; Abi> Da $>$ wud Sulaima $>$ n Ibn al-Asy'at, Sunan Abi> Da>wud, al-Juz'u al-Tha>ni>, al-T\}ab'ah al-U>la> (Beirut: Da $>$ r al-Kutub al-'Ilmiyyah, 1996), 305; Jala $>$ l al-Di $>$ n al-Sayu $>$ t $\} \mathrm{i}>$, Sunan al-Nasa $>\mathrm{i}>$ bi syarh al-Ha $>$ fiz Jala $>$ l al-Di $>\mathrm{n}$ al-Sayu $>\mathrm{t}\} \mathrm{i}$, al-Mujallad al-Ra>bi'ah, (Beirut: Da>r al-Kutub al-'Ilmiyyah, T.Th.), 229; Abi> 'I >sa> Muhammad Ibn 'I $>$ sa $>$ Ibn Saurah al-Tirmizi, Al-Ja $>m i$ ' al-S\}ah\}i $>>h\}$ wa huwa sunan al-Tirmizi>, al-Mujallad al-Tha>ni>, al-T'ab'ah al-U>la>, (Beirut: Da>r al-Kutub al-'Ilmiyyah, 2000), 381-382.

30 Al-Ha>kim dan al-Zahabi mengatakan bahwa Hadis ini Sahih berdasarkan syarat Bukhari, namun beliau tidak meriwayatkannya. Lihat: Software maktabah sya>milah, Al-Ha>kim, al-Mustadrak, Kita>b alAda $>$ \}hi>, Juz IV, 257.

$31 \mathrm{Abi}>$ Da $>$ wud Sulaima $>$ n Ibn al-Asy'at, Sunan Abi $>$ Da $>w u>d$, Kita $>b$ al-Jiha $>d, B a>b$ Ma yu'mar bih lin al-Qiya $>m$ 'ala $>$ aldawa $>b$ wa alBaha>im, al-Juz'u al-Tha>ni>, al-T\}ab'ah al-U>la>, (Beirut: Da>r al-Kutub al'Ilmiyyah, 1996), 226.
}

TAHDIS Volume 10 Nomor 1 Tahun 2019 


\section{d. Hadis yang artinya:}

Sabda Nabi SAW.:"Seorang wanita diazab karna seekor kucing yang dikurung sampai mati. Wanita itu masuk neraka karnanya. Dia tidak memberi makan dan (tidak juga) minum kepada kucing itu ketika dia menawannya. Dia juga tidak melepaskannya agar dapat makan serangga-serangga yang ada di bumi." (H.R. al-Bukhari dan Muslim). ${ }^{32}$

Hadis-hadis tentang tumbuhan dan binatang ini sejalan dengan apa yang dijelaskan oleh Pak Quraish Shihab, sebagaimana yang dikatakannya: bahwa jangankan manusia, binatang dan tumbuh-tumbuhan pun mmperoleh rahmat-Nya. Sebelum Eropa mengenal organisasi pecinta binatang, Rasul SAW. telah mengajarkan perlunya mengasihi binatang. Banyak sekali pesan beliau menyangkut hal ini, dimulai dari perintah tidak membebaninya melebihi kemampuannya sampai dengan perintah mengasah pisau terlebih dahulu sebelum menggunakannya menyembelih (HR. Muslim); Belia juga memperingatkan bahwa ada seorang wanita masuk neraka karena mengurung seekor kucing hingga akhirnya mati tanpa memberinya makan dan tidak pula melepaskannya mencari makan sendiri ( H.. Bukhari dan Muslim mealui 'Umar). Dalam ajaran Nabi pembawa rahmat itu, terlarang memetik bunga sebelum mekar, atau buah sebelum matang, karena tugas manusia adalah mengantar semua makhluk menuju tujuan

${ }^{32}$ Ahmad Ibn 'Ali> Ibn Hajar al-Asqla $>$ ni $>$, Fath $a l-B a>r i>$, Kita $>b$ alsyarb wa al-Musa>qa>t - al-Syarb, Ba> Fadl saqy al-Ma>'; Hadis No. 2365. AlJuz'u al-Kha>mis, (Al-Qa>hirah: al-Maktabah al-salafiyyah, 1407H)50; Abi> al-Husein Muslim Ibn al-Hajja $>\mathrm{j}$, S\}ah\}i>h\} Muslim, Kita>b al-Birr wa alS\}ilah wa al-Adab, Ba>b Tahri>m ta'zi>b al-Hirrah wa nahwiha> min alHayawa>n allazi $>l a>y u$ "zi $>$, al-T\}ab'ah al-Tha>niyah, (Beirut: Da $>\mathrm{r}$ al-Kutub al-'Ilmiyyyah, 2003), 1012.

TAHDIS Volume 10 Nomor 1 Tahun 2019 
penciptaannya. Kembang diciptkan antara lain agar mekar sehingga lebah datang mengisap sarinya, dan mata menjadi senang memandangnya. Bahkan benda-benda tak bernyawa pun mendapat kasih sayang beliau. Ini antara lain terlihat ketika beliau memberi nama-nama bagi benda-benda khusus beliau. Pedang beliau diberi nama Dzul Fiqar, perisainya diberi nama Dzat al-Fadhul, gelas minumannya diebri nama ashShadir, dan lain-lain. Itu semua untuk mengesankan bahwa benda-benda tak bernyawa itu, bagaikan memiliki kepribadian yang juga membutuhkan rahmat dan kasih sayang dan persahabatan. ${ }^{33}$

Dari paparan Hadis-hadis di atas, terbukti bahwa ajaran Islam, ajaran yang komprehensif. Dalam hal berbuat baik, Islam mengajarkan pada kita agar tidak hanya berbuat baik pada manusia, tapi juga pada lingkungan, tumbuh-tumbuhan dan binatang-binatang. Jadi perintah menyayangi tumbuhan dan binatang, sudah ada sejak Islam itu lahir. Sekaligus membuktikan, bahwa ajaran Islam adalah ajaran yang sempurna. Cukuplah pada Rasulullah SAW. sebagai contoh yang baik kepada kita.

33 M. Quraish Syihab, Tafsir al-Misbah, Cet. I (Jakarta: Lentera Hati, 2002), 520-521. 


\section{DAFTAR PUSTAKA}

Anas, Malik Ibn. T.Th. Muwatta' Malik, Kitab al-Qadr, Bab alNahy 'an al-Qaul bi al-Qadr,al-Juz'u al-Awwal, T.Tp.: Maktabah al-Taufiqiyyah.

'Amrah, Mustafa Muhammad. 1994. Jaudahir al-Bukhari wa Syarh al-Qastalani, Kitab al-Muzara'ah, Bab Fadl alZar'u wa al-Gars, ( T.Tp.: Dar al-Fikr.

al-Asy'at, Abi Dawud Sulaiman. 1996.Sunan Abi Dawud, Kitab al-Jihad, Bab fi karahiyah harq al-'adw, al-Juz'u alThani, al-Tab'ah al-Ula, Beirut: Dar al-Kutub al'Ilmiyyah.

Al-'Asqalani, Ahmad Ibn 'Ali Ibn Hajar. 1986. Fath al-Bari bisyarh sahih al-Bukhari, Kitab al-Mazalim, Bab La yuzlimu Muslim wala yuslimuhu, al-Qahirah: Dar alDiyan li al-Turath.

Fakhr, Muhammad al-Razi. 2005. Tafsir Al-Fakhr al-Razi, alMujallad al-Tasi', T.Tp. :Dar al-Fikr.

http://deden11410217.blogspot.com/2013/05/keseimbangan -dunia-akhirat.html. Diakses pada tanggal 09, Juni 2014.

http://kbbi.web.id/komprehensif. Diakses tanggal 09 Juni 2014.

al-Hajjaj, Abi al-Husain Muslim Ibn. 2003. Sahih Muslim, Kitab al-Siyam, Bab al-Nahy 'an Saum al-Dahr liman tadarrara bih, al-Tab'ah al-Thaniyah, Beirut: Dar alKutub al-'Ilmiyyah.

Nata, Abuddin. 2011. Studi Islam Komprehensive, Jakarta: Kencana Prenada Media Group.

TAHDIS Volume 10 Nomor 1 Tahun 2019 
$\mathbf{8 0}$ | Universalitas Ajaran Islam

Nata, Abuddin. 2013. Metodologi Studi Islam, Cet. XX, Jakarta: PT Raja Grafindo Persada.

Nasution, Harun. 1985. Islam Ditinjau dari Berbagai Aspeknya, Jilid I. Jakarta: Penerbit Universitas Indonesia.

Al-Qasimi, Muhammad Jamal al-Din. 1997. Tafsir al-Qasimi, almujallad al-Thaniyah, Beirut: Dar al-Kutub al-'Ilmiyyah.

Al-Qurtubi, Abi 'Abdillah Muhammad ibn Ahmad al-Ansori. 1935. Al-Jami' al-Ahkam al-Qur'an, al-Juz'u al-Awwal, al- Tab'ah al-Thalitha, Al-Qahirah: Dar al-Kutub alMishriyyah.

Syihab, M. Quraish. 2002. Tafsir al-Misbah, Cet. I. Jakarta: Lentera Hati.

Sofware Makatabah Syamilah, al-Tirmizi, Jam'u al-Jawami', au al-Jami' al-Kabir, Bab harf al-Lam, al-Juz'u al-Awwal.

Al-Sayuti, Jalal al-Din. T.Th. Sunan al-Nasai, Kitab al-Siyam, Bab Saum 'asyrah Ayyam min al-Syahr, al-Mujallad al-Thani, Beirut: Dar al-Kutub al-'Ilmiyyah.

Software maktabah syamilah, Al-Hakim, al-Mustadrak, Kitab alAdahi, Juz IV, 257.

Al-Tabari, Abi Ja'far Muhammad Ibn Jarir. 1999. Tafsir alTabari, Mujallad al-Rabi'ah, al-Tab'ah al-Thalithah. Beirut: Dar al-Kutub al-'Ilmiyyah.

al-Tirmizi, Abi 'Isa Muhammad Ibn 'Isa Ibn Saurah. 2000. alJami' al-Sahih wa huwa sunan al-Tirmizi, al-Mujallad alThani, al-T'ab'ah al-Ula, Beirut: Dar al-Kutub al'Ilmiyyah.

Wahid, 'Abdurrahman. 2006. Islamku, Islam anda Islam Kita, Agama Masyarakat Negara Demokrasi, Cet. I. Jakarta: The Wahid Institute.

TAHDIS Volume 10 Nomor 1 Tahun 2019 